\title{
LETTER
}

\section{Accuracy in diagnosis of allergy to $\beta$-lactams}

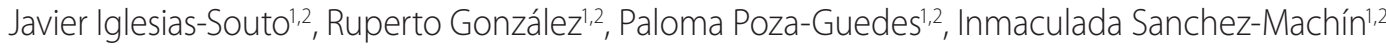 \\ and Victor Mathe ${ }^{* 1,2,3}$ \\ See related research by Gonçalves-Pereira and Póvoa, http://ccforum.com/content/15/5/R206
}

We have read the interesting paper recently published in Critical Care [1]. In the issue of pharmacodynamics of $\beta$ lactams we missed a particular subject: allergy, subtle but sometimes important in intensive and critical care units since clinicians usually manage patients labelled as 'allergic' without having been studied and based only on clinical history [2]. This creates a health resource problem and leads to use alternative treatments in most cases with a higher cost [3].

We would like to contribute in this issue by describing our experience of reaching a reliable diagnosis in subjects assessed for immediate drug allergy reaction (2001 to 2010) [2]. Diagnosis was supported by a skin test [4], and if skin tests were negative by a single-blind drug challenge test [5] (see Table 1). Nursing and physician staff were present with full resuscitation delivery.

The results are shown in Table 2, with 3,426 total studies involving antibiotics, 4,867 drug challenge tests performed, and 159 positive cases (7\%) with $\beta$-lactams. Only 114 patients were not studied (refusal or rejected). Unquestionably, the most problematic group of antibiotics was penicillins, including aminopenicillins. It is remarkable that 21 patients with a negative skin test suffered a positive oral drug challenge test, more evident in the latter studied period, possibly explained by the lower sensitivity of the skin test for the most currently used aminopenicillins.

Finally, we would like to encourage allergological studies for an accurate diagnosis of drug allergy, a common problem in clinical practice that can influence the decisions on prescription drugs.

\section{Authors' contributions}

JI-S was the main researcher in the fieldwork. IS-M and PP-G collaborated on recruiting the data. RG was responsible at the Drug Allergy Unit (2007 to 2010), and with VM designed most of the current diagnosis protocols. VM was the principal senior investigator, had the original idea, and was responsible at

*Correspondence: Victor.Matheu@med.lu.se

¿Unidad de Investigación, Complejo Hospital Universitario NS Candelaria, Edificio de Traumatologia, 2a Planta, Carretera del Rosario, 145 Santa Cruz de Tenerife

38010, Spain

Full list of author information is available at the end of the article the Drug Allergy Unit (2004 to 2007). All authors collaborated in the fieldwork and approved the final version of the manuscript,

\section{Competing interests}

The authors declare that they have no competing interests.

\section{Acknowledgements}

Compilation of data was recorded following the European standards of data protection and the study was approved by the Clinical Research Ethics Committee in 2010 (HUNSC: PI-14/10). Written informed consent was obtained for every patient involved in the study following good clinical practice procedures. The authors declare that the source of funding for this project was exclusively the CHUNSC \& Servicio Canario de Salud. VM held a grant for Clinical Research from Institituto de Salud Carlos III -FIS - Programa de Intensificación de Actividad para Investigadores Clínicos 2010 to 2011. The authors would like to thank to every staff member of the unit during the period 2001 to 2010, specially the following registered nurses: E Diaz, E Rodriguez, J Vera and S Garcia.

\section{Author details}

'Drug Allergy Unit, Hospital del Tórax-Ofra, CHUNSC, Servicio Canario de Salud, Ofra s/n Tenerife 38320, Spain. ${ }^{2}$ Unidad de Investigación, Complejo Universitario NS Candelaria, Edificio de Traumatologia, 2a Planta, Carretera del Rosario, 145 Santa Cruz de Tenerife 38010, Spain. ${ }^{3}$ Department of Clinical Sciences, Division IV, Box 117, Lund University, 22185 Lund, Sweden.

Published: 9 March 2012

\section{References}

1. Goncalves-Pereira J, Povoa P: Antibiotics in critically ill patients: a systematic review of the pharmacokinetics of $\beta$-lactams. Crit Care 2011, 15:R206.

2. Gomes E, Cardoso MF, Praca F, Gomes L, Marino E, Demoly P: Self-reported drug allergy in a general adult Portuguese population. Clin Exp Allergy 2004, 34:1597-1601.

3. Gruchalla RS, Pirmohamed M: Clinical practice. Antibiotic allergy. N Engl J Med 2006, 354:601-609.

4. Gadde J, Spence M, Wheeler B, Adkinson NF, Jr: Clinical experience with penicillin skin testing in a large inner-city STD clinic. JAMA 1993, 270:2456-2463.

5. Aberer W, Bircher A, Romano A, Blanca M, Campi P, Fernandez J, Brockow K, Pichler WJ, Demoly P: Drug provocation testing in the diagnosis of drug hypersensitivity reactions: general considerations. Allergy 2003, 58:854-863.

6. Matheu V, Pérez E, González R, Poza P, de la Torre F, Sánchez-Machín I, GarcíaRobaina JC: Assessment of a new brand of determinants for skin testing in a large group of patients with suspected beta-lactam allergy. J Investig Allergol Clin Immunol 2007, 17:257-260.

7. Torres MJ, Blanca M, Fernandez J, Romano A, Weck A, Aberer W, Brockow K, Pichler WJ, Demoly P; ENDA; EAACI Interest Group on Drug Hypersensitivity: Diagnosis of immediate allergic reactions to beta-lactam antibiotics. Allergy 2003, 58:961-972.

\section{doi:10.1186/cc11193}

Cite this article as: Iglesias-Souto J, et al:: Accuracy in diagnosis of allergy to $\beta$-lactams. Critical Care 2012, 16:414. 
Table 1. Diagram for diagnosis of penicillin allergy

\begin{tabular}{|c|c|c|c|}
\hline$\beta$-lactam & Skin prick test (mg/ml) & $\begin{array}{l}\text { Intradermal } \\
(\mathrm{mg} / \mathrm{ml})\end{array}$ & $\begin{array}{l}\text { Provocation } \\
\text { test }(\mathrm{mg})\end{array}$ \\
\hline Penicillins & PPL $5 \times 10^{-5} \mathrm{mmol} / /$; MDM $2 \times 10^{-2} \mathrm{mmol} / /$; penicillin G 20-25a & As SPT & $5,25,100,250,500$ \\
\hline \multicolumn{4}{|l|}{ Cephalosporins } \\
\hline Oral (cefaclor, cefadroxil, cefixime, cefuroxime) & $2-100$ & $2^{\mathrm{a}}$ & $5,25,125,500$ \\
\hline
\end{tabular}

Diagnosis was supported by skin test (ST) (skin prick and intradermal test) $[5,6]$, and if STs were negative by a single-blind drug challenge test (DChT) with increasing doses of the suspected drug $[3,4]$ every 60 minutes until the usual daily dose was administered or symptoms occurred (some of the symptoms previously described were present) [2]. If symptoms appeared more than 3 hours after the last dose of the DChT, a new DChT was proposed and scheduled. PPL, major determinant of

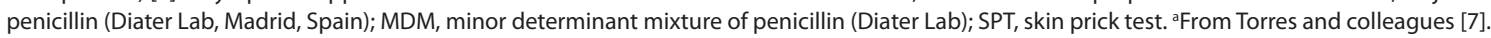

Table 2. Data for drug allergy studies 2001 to 2010

\begin{tabular}{lcccc}
\hline Group & $\begin{array}{c}\mathbf{2 0 0 1} \text { to } \\
\mathbf{2 0 0 5}\end{array}$ & $\begin{array}{c}\mathbf{2 0 0 6} \text { to } \\
\mathbf{2 0 1 0}\end{array}$ & Total & Percentage \\
\hline Penicillins & $676(76)$ & $1,329(75)$ & $2,025(151)$ & 7.4 \\
$\quad$ Skin prick test & $676(10)$ & $1,329(08)$ & $(18)$ & \\
$\quad$ Intradermal test & $676(62)$ & $1,329(50)$ & $(112)$ & \\
$\quad$ Challenge & $604(4)$ & $1,271(17)$ & $(21)$ & \\
Cephalosporins & $24(2)$ & $160(3)$ & $184(5)$ & 2.7 \\
$\quad$ Skin prick test & $24(2)$ & $160(2)$ & $(4)$ & \\
Challenge & $22(0)$ & $158(1)$ & $(1)$ & \\
Others & $82(1)$ & $38(2)$ & $120(3)$ & 2.5 \\
$\quad$ Skin prick test & $82(1)$ & $38(1)$ & $(2)$ & \\
Challenge & $81(0)$ & $37(1)$ & $(1)$ & \\
Total & 782 & 1,527 & $2,309(159)$ & 6.9 \\
\hline
\end{tabular}

Data presented as total number of patients (number of patients diagnosed positive). Symptoms were not limited only to the skin (urticaria, erythema, angioedema), but also included confusion, collapse, unconsciousness, hypotension, diaphoresis, vomiting, presyncope, dyspnoea, stridor, wheeze, chest/throat tightness, nausea/vomiting, and abdominal pain. ${ }^{a}$ Included carbapenems (imipinem, meropenem) and monobactams (aztreonam). 